\section{Schwindender Schutz nach fünfmaliger Pertussis-Impfung}

Mit jedem Jahr, das seit der fünften Impfung mit azellulärer Pertussisvakzine vergeht, schwindet der Impfschutz. Dies zeigen die Ergebnisse einer Studie aus den USA.

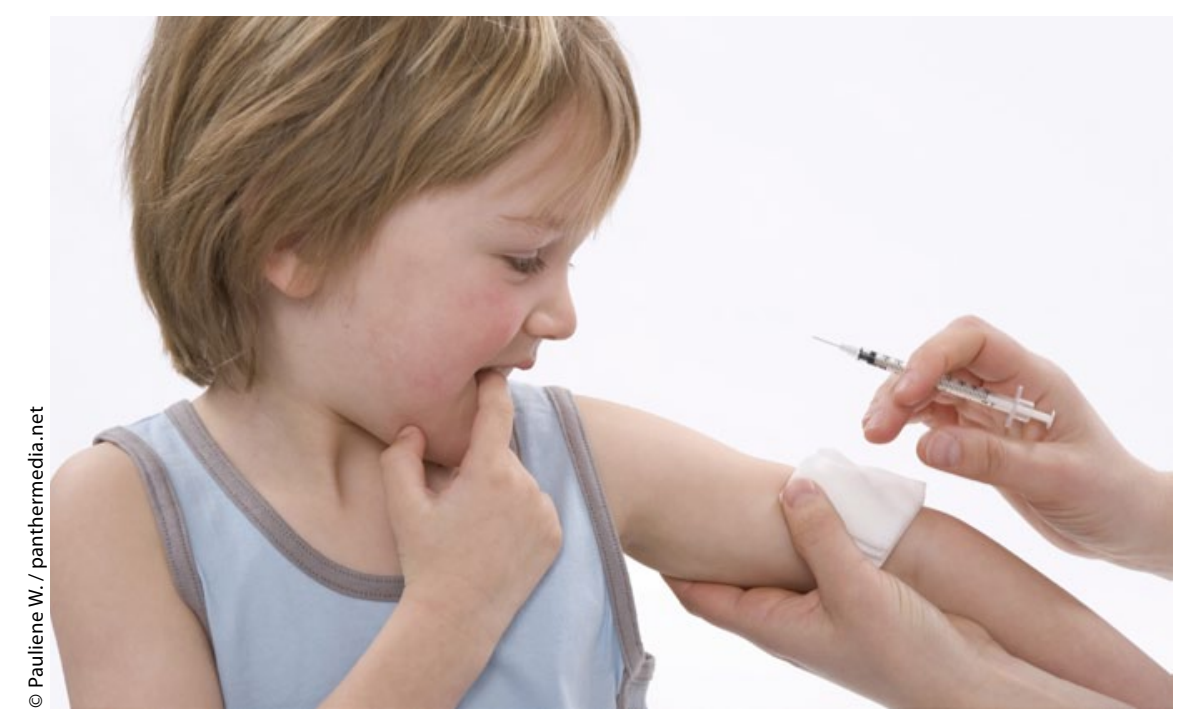

Schützt die Impfung gegen Keuchhusten? Ja, aber mit abnehmender Wirkung. n den Vereinigten Staaten wird ebenso wie in vielen anderen Ländern beobachtet, dass es alle drei bis fünf Jahre zu einem deutlichen Ausbruch von Pertussis kommt, obwohl der Durchimpfungsgrad gut ist. So kam es im Jahr 2010 in Kalifornien zum größten Pertussis-Ausbruch seit 1958. In diesem Bundesstaat der USA wurden seit den späten 1990erJahren ausschließlich azelluläre Pertussisvakzine eingesetzt, in der Regel als Kombinationsimpfstoffe mit Diphtherie und Tetanus (DTaP). In Kalifornien ist die fünfmalige Impfung mit dem genannten Impfstoff die Voraussetzung für die Schulaufnahme. Die letzte Dosis wird in der Regel im Alter zwischen vier und sechs Jahren verabreicht.

Die Arbeitsgruppe von Nicola Klein aus Oakland, Kalifornien, hat sich zur Aufgabe gemacht den Rückgang der Schutzwirkung des Impfstoffes gegen Pertussis bei Kindern, die mindestens fünfmal geimpft worden waren, zu quantifizieren. Sie konnten die Daten der Kaiser Permanente Organisation nutzen. Die Organisation fungiert nicht nur als Krankenkasse, sondern betreibt in Nordkalifornien auch 68 Kranken- population bestand aus 277 Kindern, die zwischen vier und zwölf Jahre alt waren und bei denen die PCR für Pertussis positiv war. Diese wurden mit 3.318 PCRnegativen Kontrollen und 6.086 „matched controls" verglichen.

Es zeigte sich, dass die Häufigkeit einer positiven Diagnose zunahm, je länger die fünfte Impfung zurücklag. Bei PCR-positiven Kindern war die Wahrscheinlichkeit höher, dass die fünfte Impfung länger zurücklag als bei PCRnegativen Kontrollen ( $\mathrm{p}<0,001)$ und "matched controls“ $(\mathrm{p}=0,005)$. Der Vergleich mit PCR-negativen Kontrollen ergab eine Odds Ratio für Pertussis von 1,42 pro Jahr. Dies besagt, dass das Risiko, Keuchhusten trotz fünfmaliger Impfung mit azellulärer Pertussisvakzine zu akquirieren, in jedem Jahr nach der Impfung um $42 \%$ steigt. Hervorzuheben ist, dass alle 277 Fälle leicht verliefen. Eine Hospitalisierung war in keinem Fall erforderlich.

Klein NP et al. Waning protection after fifth dose of acellular pertussis vaccine in children. N Engl J Med 2012; 367: 1012-9

häuser. Sie hat 3,2 Millionen Mitglieder. Die Pertussisdiagnose erfolgte auf der Basis einer PCR. Alle Laboruntersuchungen wurden in einem Labor durchgeführt. Es wurden nur Kinder aufgenommen, bei denen die Diagnose wenigstens zwei Wochen nach der fünften Impfung gestellt wurde.

Im Rahmen der Untersuchung wurden 27.912 PCR-Untersuchung auf Bordetella pertussis vorgenommen. Davon waren $1.512(5,4 \%)$ positiv. Die Studien-
Kommentar: Diese Untersuchung zeigt, dass auch nach fünfmaliger Pertussis-Impfung der niedergelassene Kinderarzt bei verdächtigem klinischen Bild die Diagnose "Keuchhusten" erwägen muss. Sie zeigt weiter, dass bei Auffrischungsimpfungen wie von der STIKO empfohlen, unbedingt die Keuchhustenkomponente mit eingeschlossen werden muss. Eine Verbesserung des Impfstoffes ist wünschenswert.

Dr. Hartmut Koch

\section{Ist Stillen ein Mittel gegen Schnarchen?}

In einer US-amerikanischen Studie wurde das Schnarchverhalten von 249 Kindern im Alter zwischen zwei und drei Jahren aus dem Großraum von Cincinnati untersucht. Es stellte sich heraus, dass die Kinder, die nach Angaben der Eltern wenigstens in zwei Nächten pro Woche "laut schnarchten", signifikant eher an Hyperaktivität, Depressionen oder Aufmerksamkeitsstörungen litten als Kinder, die nicht oder selten schnarchten. Kein Kind, das mindestens zwölf Monate lang gestillt worden war, schnarchte nach Angaben der Eltern mehr als zweimal pro Woche. Dagegen gaben die Eltern jener Kinder an, die nie oder höchstens einen Monat lang gestillt worden waren, dass ihr Nachwuchs stark schnarcht. Eine Erklärung könnte nach Ansicht der Autoren sein, dass die "Schnarcher" eher als in besser situierten Familien Passivraucher sind. Peter Leiner
Beebe D W et al. Pediatrics 2012; 130: 382-9 